\title{
Increased uncoupling protein 3 content does not affect mitochondrial function in human skeletal muscle in vivo
}

\author{
Matthijs K.C. Hesselink, ${ }^{1}$ Paul L. Greenhaff, ${ }^{2}$ Dimitru Constantin-Teodosiu, ${ }^{2}$ \\ Eric Hultman, ${ }^{3}$ Wim H.M. Saris, ${ }^{4}$ Robby Nieuwlaat, ${ }^{1}$ Gert Schaart,${ }^{1}$ Esther Kornips,,${ }^{1,4}$ \\ and Patrick Schrauwen ${ }^{4}$
}
${ }^{1}$ Department of Movement Sciences, Nutrition and Toxicology Research Institute Maastricht, Maastricht University, Maastricht, The Netherlands
${ }^{2}$ School of Biomedical Sciences, University Medical School, Queen's Medical Centre, Nottingham, United Kingdom ${ }^{3}$ Department of Clinical Chemistry, Huddinge University Hospital, Karolinska Institute, Stockholm, Sweden
${ }^{4}$ Department of Human Biology, Nutrition and Toxicology Research Institute Maastricht, Maastricht University, Maastricht, The Netherlands

\begin{abstract}
Phosphocreatine ( $\mathrm{PCr}$ ) resynthesis rate following intense anoxic contraction can be used as a sensitive index of in vivo mitochondrial function. We examined the effect of a diet-induced increase in uncoupling protein 3 (UCP3) expression on postexercise $\mathrm{PCr}$ resynthesis in skeletal muscle. Nine healthy male volunteers undertook 20 one-legged maximal voluntary contractions with limb blood flow occluded to deplete muscle PCr stores. Exercise was performed following 7 days consumption of low-fat (LF) or high-fat (HF) diets. Immediately following exercise, blood flow was reinstated, and muscle was sampled after 20,60, and 120 seconds of recovery. Mitochondrial coupling was assessed by determining the rate of $\mathrm{PCr}$ resynthesis during recovery. The HF diet increased UCP3 protein content by approximately $44 \%$ compared with the LF diet. However, this HF diet-induced increase in UCP3 expression was not associated with any changes in the rate of muscle $\mathrm{PCr}$ resynthesis during conditions of maximal flux through oxidative phosphorylation. Muscle acetylcarnitine, free-creatine, and lactate concentrations during recovery were unaffected by the HF diet. Taken together, our findings demonstrate that increasing muscle UCP3 expression does not diminish the rate of $\mathrm{PCr}$ resynthesis, allowing us to conclude that the primary role of UCP3 in humans is not uncoupling.
\end{abstract}

J. Clin. Invest. 111:479-486 (2003). doi:10.1172/JCI200316653.

\section{Introduction}

Cloning of the human uncoupling protein 1 (UCP1) homologue, UCP3, has initiated research toward the putative role of this novel protein (1). On the basis of its amino acid sequence homology (approximately $58 \%$ ) with UCP1, a similar role to that of UCP1 - that is, lowering the proton motive force and reducing ADP phosphorylation and thereby increasing energy expenditure (a process referred to as uncoupling) - has been attributed to UCP3. The supposed uncoupling potential of UCP3, together with the chromosomal

Received for publication August 13, 2002, and accepted in revised form November 19, 2002.

Address correspondence to: Matthijs Hesselink, Nutrition and Toxicology Research Institute Maastricht (NUTRIM), Department of Movement Sciences, Maastricht University, PO Box 616, NL-6200 MD, Maastricht, The Netherlands. Phone: 31-433881317; Fax: 31-433670972;

E-mail: matthijs.hesselink@bw.unimaas.nl.

Conflict of interest: The authors have declared that no conflict of interest exists.

Nonstandard abbreviations used: phosphocreatine (PCr); uncoupling protein 3 (UCP3); low fat (LF); high fat (HF); T3 (thyroxine); maximal voluntary knee contractions (MVCs); human UCP3 (hUCP3); general linear model (GLM). mapping in the vicinity of genes associated with obesity and diabetes $(2,3)$, has contributed to the idea that UCP3 is a candidate protein involved in the development of obesity. Indeed, a positive relation has been observed between UCP3 mRNA levels and energy expenditure in Pima Indians (4). However, the proposed physiological role of UCP3 as a mitochondrial uncoupler, and thus its relation to energy expenditure and obesity, is still debatable. In particular, studies in which the level of UCP3 has been overexpressed by genetic manipulation have had conflicting results (5-7). Thus, on the one hand, overexpression of UCP3 lowered the mitochondrial membrane potential in yeast $(8,9)$ and increased state 4 respiration in mitochondria isolated from mice skeletal muscle (10). On the other hand, however, expressing human UCP3 in yeast to supraphysiological levels did not induce uncoupling and therefore was considered an artifact (7). Similarly, mitochondria derived from transgenic mice overexpressing UCP3 by approximately 20 -fold showed only noninducible uncoupling (6). Finally, mitochondria isolated from $U C P 3$-ablated mice have been shown to be more tightly coupled in vitro (11, 12 ) and in vivo (13) in some but not all (6) studies. 
However, it should be noted that UCP3-ablated mice responded normally to fasting and lacked an apparent phenotype change $(11,12)$.

A more physiological intervention demonstrated that a fasting-induced increase in UCP3 expression (two- to threefold) in rats did not affect mitochondrial coupling in vitro (14) or in vivo (15). However, when T3 (thyroxine) treatment was used, upregulation of UCP3 (approximately threefold) coincided with increased uncoupling in vivo (16) and in vitro (17-19).

The inconsistency with regard to increased UCP3 expression being associated with uncoupled mitochondrial respiration under physiological conditions, together with the observation that substances present under physiological conditions (like superoxide and GDP) can induce or inhibit the uncoupling activity of UCP3, underscores the need to investigate this phenomenon in humans. Manipulation of UCP3 content under physiological conditions, with simultaneous assessment of the coupling of mitochondria in their native environment, should provide important information whether the primary role of UCP3 is to uncouple mitochondria and hence to modulate energy expenditure.

In the present study, high-intensity exercise with limb blood flow occlusion was used as a model to deplete muscle PCr stores. To test whether the primary role of UCP3 is to uncouple mitochondrial respiration, we used the rate of $\mathrm{PCr}$ resynthesis during subsequent recovery with limb blood flow reinstated. On the basis of earlier reports relating to the stimulatory effect of high-fat (HF) feeding on UCP3 mRNA expression (20-22), UCP3 protein content was manipulated by feeding healthy human subjects an HF diet. We hypothesized that an HF diet-induced increase in UCP3 protein content would decrease mitochondrial energy coupling in vivo, which would be reflected by a decrease in the rate of $\mathrm{PCr}$ resynthesis during recovery.

\section{Methods}

Subjects. Nine healthy, physically inactive, normotensive, male, Caucasian subjects enrolled in the study after giving their written informed consent to take part. Subject characteristics are shown in Table 1 . The institutional Medical-Ethical Committee of Maastricht University approved the study.

Experimental protocol. After a preliminary familiarization visit, subjects were requested to visit the laboratory on two further occasions each separated by at least 12 days. On the first occasion, subjects reported to the laboratory after consuming a prescribed low-fat (LF) diet for 7 days (a venous blood sample was also obtained from an anticubital vein after an overnight fast on day 6). On reporting to the laboratory, subjects performed a high-intensity exercise test on a Cybex II dynamometer (Ronkonkoma, New York, USA). The leg to be exercised was positioned in line with the lever arm of the Cybex II isokinetic dynamometer, and a strap was placed securely around the ankle to ensure transfer of force. To minimize movement, subjects were secured around the midriff and the lower-thigh region of the limb to be exercised. Before the initiation of exercise, subjects were prepared for muscle biopsy sampling by having three incisions (each separated by $2.5 \mathrm{~cm}$ ) through the skin and muscle fascia under local anesthesia ( $2 \%$ xylocaine). After this procedure, an inflatable limb occlusion cuff was placed around the upper portion of the leg to be exercised and was inflated to more than $180 \mathrm{~mm} \mathrm{Hg}$ while subjects rested in the chair of the Cybex ergometer. The cuff was maintained at this pressure for 3 minutes (in an attempt to deplete muscle oxygen stores), and subjects then performed 20 maximal voluntary knee contractions (MVCs) at an angular velocity of $90^{\circ}$ per second. The subjects were verbally encouraged to produce maximal effort every 4 seconds, the rhythm being indicated by a metronome. Force generated during exercise was recorded on a PC.

Immediately after exercise (less than 2 seconds), limb blood flow was reinstated, and needle muscle biopsies (23) were taken 20,60, and 120 seconds after the reinstatement of blood flow, as $\mathrm{PCr}$ resynthesis is known to be almost complete during the initial 2 minutes of recovery in this experimental model (24). All muscle biopsy samples were snap frozen by plunging the needle into liquid nitrogen directly after removal from the limb. One portion of the sample was subsequently freeze dried and stored at $-80^{\circ} \mathrm{C}$, and the remainder was stored wet in liquid nitrogen.

After this exercise session, HF diets were handed out; subjects consumed this HF diet, which was isocaloric with respect to the LF diet, for 7 days. During this period, subjects undertook the same experimental procedures as those described above. To prevent trauma-induced alterations in $\mathrm{PCr}$ resynthesis, the leg performing the first experimental trial was randomly chosen, and the contralateral leg was exercised during the second experimental trial. Blood samples were analyzed for lipid-related parameters, and muscle samples were analyzed for UCP3 protein content, energy-rich phosphates, creatine, lactate, free-carnitine, and acetylcarnitine concentrations.

Pretesting trials. Body composition was assessed after an overnight fast using the hydrostatic weighing. Residual lung volume was measured by the heliumdilution technique using a spirometer (Volugraph 2000, Mijnhardt, The Netherlands). Percentage body fat was calculated using Siri's equation (25). Body mass was measured before and after LF and HF feeding.

\section{Table 1}

Subject characteristics

\begin{tabular}{lc}
\hline Parameter & Mean $( \pm$ SEM) \\
Age $(\mathrm{yr})$ & $21.3(0.6)$ \\
Height $(\mathrm{m})$ & $1.84(0.03)$ \\
Weight $(\mathrm{kg})$ & $79.1(7.0)$ \\
BMl $\left(\mathrm{kg} / \mathrm{m}^{2}\right)$ & $23.3(1.6)$ \\
Body fat $(\%)$ & $14.4(3.6)$ \\
\hline
\end{tabular}


Diets. Metabolizable energy intake and macronutrient composition of the diet was calculated using the Dutch food composition table (26). In this table, metabolizable energy is calculated by multiplying the amount of protein, fat, and carbohydrate with the Atwater factors $(16.74,37.66$, and $16.74 \mathrm{~kJ} / \mathrm{g}$ for protein, fat, and carbohydrate, respectively). The HF diet consisted of $60 \%$ of energy as fat, $25 \%$ of energy as carbohydrate, and $15 \%$ of energy as protein. The LF diet consisted of $30 \%$ of energy as fat, $55 \%$ of energy as carbohydrate, and $15 \%$ of energy as protein. Subjects' energy requirements were based on calculated basal metabolic rate (27) multiplied by an activity level of 1.7 (28). Food items were packed in daily portions and were handed out every other day. Subjects were instructed to strictly adhere to the diet with ad libitum consumption of water and tea.

Blood and muscle analysis. Fasting venous blood samples collected on day 6 after both diets was collected in tubes containing EDTA and was immediately centrifuged at $4,000 \mathrm{rpm}$ for 10 minutes at $4^{\circ} \mathrm{C}$. Plasma was frozen in liquid nitrogen and stored at $-80^{\circ} \mathrm{C}$ until further analysis of FFAs (Wako NEFA C test kit; Wako chemicals, Neuss, Germany), glycerol, and triglycerides (glycerol kinase-lipase method; Boehringer, Mannheim, Germany) was undertaken. All analyses were performed on an automated centrifugal spectrophotometer (Cobas Fara, La Roche, Basel, Switzerland).

Freeze-dried muscle samples were dissected free from visible blood and connective tissue and powdered, and approximately $10 \mathrm{mg}$ was extracted in 0.5 $\mathrm{M}$ perchloric acid containing $1 \mathrm{mM}$ EDTA. After centrifugation, the neutralized supernatant $(2.2 \mathrm{M}$ $\mathrm{KHCO}_{3}$ ) was used for spectrophotometric analyses of $\mathrm{PCr}$, creatine, and lactate (29). The same extract was used for determination of free-carnitine and acetylcarnitine concentrations (30).

Western blotting and antibody validation. The wet muscle tissue samples obtained at 20,60, and 120 seconds were pooled and homogenized in ice-cold Tris-EDTA buffer at $\mathrm{pH} 7.4$ to determine UCP3 protein content by Western blotting. The homogenates were sonicated four times for 15 seconds. Routine polyacrylamide SDS gel electrophoresis was performed essentially according to the procedure described by Laemmli (31). Nitrocellulose sheets were preincubated for 60 minutes with blocking buffer containing 5\% nonfat dry milk (Bio-Rad, Hercules, California, USA) and 0.05\% Tween-20 (Sigma-Aldrich, St. Louis, Missouri, USA) in PBS. An affinity-purified, previously validated (32) polyclonal antibody raised in rabbit against a 20-amino-acid peptide that comprised amino acids 147-166 of human UCP3 was used to assess UCP3 protein levels. The peptide used has no homology with UCP2. A wide range of positive and negative specificity tests was performed to validate this antibody. In immunolocalization studies, the affinitypurified antibody was used on human skeletal muscle and on H9C2 cells. H9C2 cells lack endogenous protein expression of UCP2 and UCP3; thus, untreated cells failed to show any detectable signal. In H9C2 cells transfected with human UCP3 (hUCP3), a punctate mitochondrial staining appeared, which was completely abolished after preincubation of the antibody with the peptide (32). Also, in human skeletal muscle, the antibody raised a mitochondrial signal that was undetectable after preincubation, as established by light microscopy (32). In Western blotting, the specificity was tested (Figure 1a) by using tissues known to express UCP3 at the protein level (skeletal muscle) or tissues lacking endogenous expression of UCP3 but with reported UCP2 expression (human liver, human lung, and human white adipose tissue). In addition, skeletal muscle from mice overexpressing human UCP3 (10) and their corresponding littermates was examined (Figure $1 \mathrm{~b}$ ). Similar to previous observations (32), no bands were present in human liver, human lung, human white adipose tissue, and skeletal muscle from wild-type littermates, whereas in human skeletal muscle as well as in skeletal muscle from mice overexpressing human UCP3, a clear band representing UCP3 was detected. None of the samples showed cross-reactivity with proteins of distinct molecular mass (including UCP2) in the region examined. Similar to our findings in immunolocalization studies, no band was detected in Western blotting after preincubation of the antibody with the peptide (data not shown).

Taken together, these findings have convinced us that on affinity purification, the antibody referred to as 1331 (Eli Lilly and Co., Indianapolis, Indiana, USA) specifically recognizes human UCP3 in skeletal muscle without cross-reacting with any of the other uncoupling proteins presently known.

Incubation with this affinity-purified polyclonal antibody in a 1:1,000 dilution in blocking buffer was carried out overnight at room temperature with gentle shaking. After washing, blots were incubated for 60 minutes at room temperature with horseradish peroxidase-conjugated swine anti-rabbit Ig (SWARPO, DAKO, Glostrup, Denmark) diluted 1:10,000 in blocking buffer. Blots were subsequently washed for 90 minutes in $0.05 \%$ Tween-20/PBS and for 10

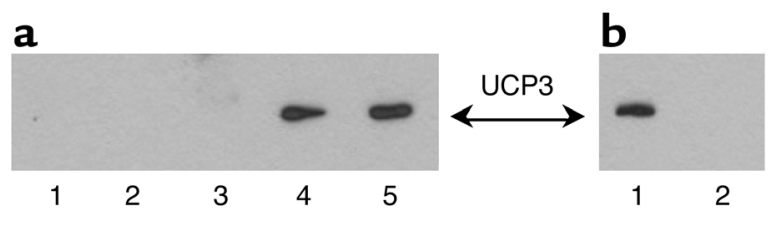

\section{Figure 1}

(a) Representative Western blot of human lung (1), human liver (2), human white adipose tissue (3), and two human vastus lateralis muscle samples (4 and 5) after loading similar amounts of protein. (b) Western blot of medial gastrocnemius muscle from a transgenic mouse overexpressing human UCP3 (1) and a wild-type littermate (2). Note the lack of cross-reactivity in tissues known to express UCP2 but not UCP3 (a) and the lack of cross-reactivity with endogenous mouse UCP3 (b). 


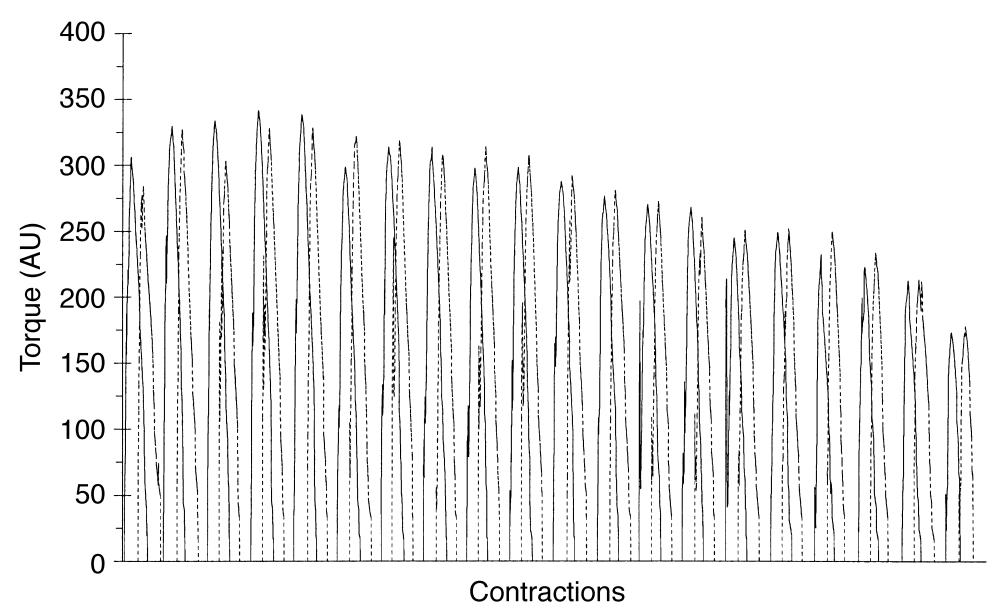

Figure 2

Muscle torque production recorded during 20 successive knee extensions. The solid line represents the LF trial, and the dashed line represents the HF trial. AU, arbitrary units.

minutes in PBS. Chemiluminescence was performed using a Super Signal West Dura Extended kit (Pierce, Rockford, Illinois, USA).

Statistics. Paired Student's $t$ tests were performed to compare the effect of both diets on blood parameters and UCP3 content. The general linear model (GLM) for multivariate analysis command (SPSS for Windows release 10.1.0) was used to perform a two-way ANOVA to examine the effect of the main factors (diet and time) on muscle metabolites.

\section{Results}

Exercise protocol. Recording of contractile performance of the knee-extensor muscles during 20 maximal voluntary contractions with limb blood flow occluded showed a gradual decline in torque production (approximately $45 \%$ ) (Figure 2). The total amount of work (area under the curve) performed after the two diets was similar, as demonstrated by the close similarity in muscle torque production throughout the 20 contractions (Figure 2). This also ensures that any metabolic differences observed between treatments could not be explained by a difference in the amount of work performed during exercise. Blood metabolites. Plasma FFAs and triglyceride concentrations after the HF diet were significantly greater than after the LF diet $(194 \pm 15 \mathrm{~mol} / \mathrm{l}$ vs. $274.1 \pm 16$ $\mathrm{mol} / \mathrm{l}, P<0.05$, and $876 \pm 300 \mathrm{~mol} / \mathrm{l}$ vs. $818.0 \pm 309$ $\mathrm{mol} / \mathrm{l}, P<0.05$, respectively). Both findings indicate good compliance with the diets.

Muscle UCP3 content and metabolite concentrations. UCP3 protein content was greater (approximately $44 \%$ ) after the HF diet than after the LH diet $(0.69 \pm 0.10 \mathrm{AU}$ vs. $0.48 \pm 0.1 \mathrm{AU}, P<0.05$ ) (Figure 3 ). Figure 4 shows muscle $\mathrm{PCr}$ concentrations at 20,60, and 120 seconds of recovery with limb blood flow reinstated. As expected, muscle $\mathrm{PCr}$ concentrations increased during recovery, but no difference in response was observed at any time point with respect to diet.
Muscle lactate and creatine concentrations declined over the course of recovery in both groups. Furthermore, no differences in lactate or creatine concentrations were observed across diets at any time point during recovery (Table 2 ).

Muscle acetylcarnitine concentrations increased during recovery in both experimental groups (Table 2). However, there was no significant difference between groups at any time point during recovery. The changes in muscle acetylcarnitine on each diet were mirrored by changes in muscle free-carnitine concentrations.

\section{Discussion}

Since the cloning of human UCP3, a UCP1 homologue, many investigators have examined the putative function of UCP3. Due to the homology of UCP3 with UCP1 (58\% amino acid identity), it was believed that UCP3 may be involved in the regulation of energy expenditure. Indeed, it has been shown that transfection of yeast with hUCP3 lowers the mitochondrial proton gradient (8), that mitochondria from mice overexpressing UCP3 have increased state 4 respiration (10), and that mitochondria from UCP3 knockout mice possess decreased state 4 respiration (11). Conversely, however, neither fasted rats in vivo (15) nor mitochondria isolated from fasted mice in vitro (33) showed increased mitochondrial proton leak, despite upregulation of UCP3. This apparent discrepancy between data derived from genetically modified animals and physiological interventions with regard to the role of UCP3 in mitochondrial uncoupling emphasizes the need to examine the effect of a physiological increase in UCP3 content on mitochondrial function in humans.

In the present study, we examined the effect of an HF diet-induced increase of UCP3 protein content on $\mathrm{PCr}$ resynthesis during recovery from anoxic exercise in humans. As $\mathrm{PCr}$ resynthesis during recovery from exercise is entirely dependent on mitochondrial respiration, it was assumed that if the primary role of UCP3

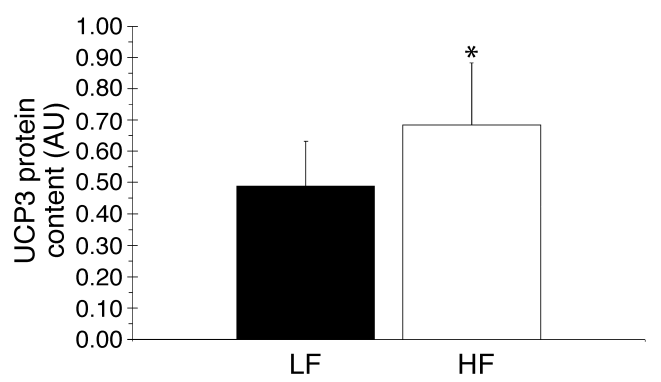

Figure 3

Muscle UCP3 protein content assessed by Western blotting for the LF and HF diets, expressed in arbitrary units $(A U)$ after scanning optical density. ${ }^{*} P<0.05$ as compared with the LF diet. 


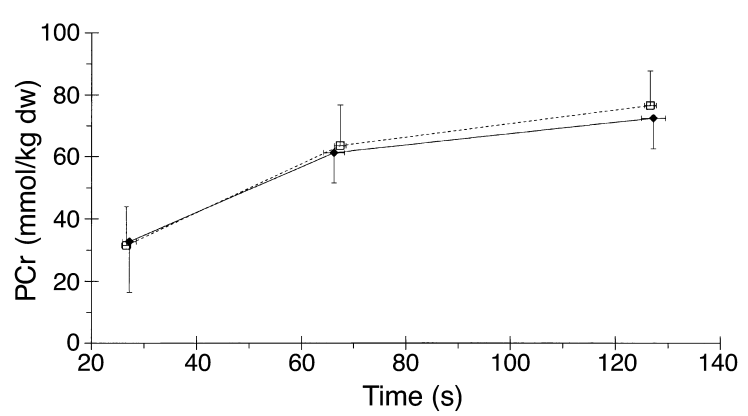

Figure 4

Muscle PCr concentrations during recovery from 20 maximal knee extensions with limb blood flow occluded. Immediately after exercise, limb blood flow was reinstated, and needle muscle biopsies were taken 20,60 , and 120 seconds after the cessation of exercise. Values represent means $\pm S D$. The solid lines represent the LF diet, and the dashed lines represent the HF diet. dw, dry weight.

is to uncouple mitochondrial respiration, any dietinduced increase in UCP3 would be reflected in vivo by the rate of $\mathrm{PCr}$ resynthesis (particularly in this model, in which $\mathrm{PCr}$ degradation during anoxic exercise is marked). The main and novel finding of the present study was that in intact human skeletal muscle, mitochondrial coupling appears not to be influenced by an HF diet-induced increase in UCP3 protein content, indicating that the primary role of UCP3 is not uncoupling. The present study also showed that feeding humans an HF diet (60\% of the energy ingested (En\%) was accounted for by dietary fat) for 7 days induces upregulation of UCP3 at the protein level in skeletal muscle that is directly in line with data from studies reporting upregulation of UCP3 mRNA expression after HF feeding (20-22).

Most of the studies examining the potential of UCP3 to affect mitochondrial coupling have examined uncoupling under resting conditions or have assessed state 3 and state 4 respiration - that is, in the presence and absence of ADP, respectively. However, the net flux through the $\mathrm{F}_{0}-\mathrm{F}_{1}$-ATPase is not maximal under these conditions. To generate maximal flux through the $\mathrm{F}_{0}-\mathrm{F}_{1}$-ATPase during recovery, we depleted muscle $\mathrm{PCr}$ stores using high-intensity exercise with limb blood flow occluded and assessed mitochondrial coupling by measuring the rate of $\mathrm{PCr}$ resynthesis during recovery with limb blood flow reinstated. It has previously been shown that during recovery from such exercise, the rate of $\mathrm{PCr}$ resynthesis reflects the net ATP synthesis rate through the $\mathrm{F}_{0}-\mathrm{F}_{1}$-ATPase (34), as both are coupled at the mitochondrial membranes by adenine nucleotide translocase and mitochondrial creatine kinase and in turn, therefore, directly reflect the extent of mitochondrial coupling in vivo (35). Thus, during the period of ischemic contraction, the intramitochondrial accumulation of reducing equivalents (36) will increase the proton gradient, and in tightly coupled mitochondria, the energy generated by this proton gradient will be diverted to phosphorylate ADP through $\mathrm{F}_{0}-\mathrm{F}_{1}$-ATPase, which will in turn determine the rate of $\mathrm{PCr}$ resynthesis during recovery when limb blood flow is reinstated. However, the flux through $\mathrm{F}_{0}-\mathrm{F}_{1^{-}}$ ATPase will be diminished in uncoupled mitochondria (37), thereby slowing the rate of $\mathrm{PCr}$ resynthesis during recovery.

Irrespective of the diet received, muscle PCr resynthesis was almost complete within 120 seconds of recovery (Figure 4), as indicated by muscle $\mathrm{PCr}$ concentrations, which were similar to resting levels (38, 39). Furthermore, there were no differences in the muscle $\mathrm{PCr}$ concentrations across the diets at any time point. If the HF diet-induced increase in UCP3 had affected mitochondrial coupling and thus net flux through the $\mathrm{F}_{0}-\mathrm{F}_{1}$-ATPase, the rate of $\mathrm{PCr}$ resynthesis would have been lower. However, we observed no effect of UCP 3 content the rate of on PCr resynthesis. Indeed, Figure 5 demonstrates not even a hint of a relationship between these two variables. This has led us to conclude that an increase in UCP3 content within the physiological range does not affect mitochondrial coupling in vivo in human skeletal muscle. This conclusion is also supported by the similarity in acetylcarnitine and free-carnitine concentrations across treatments during recovery from exercise in the present study, indicating that mitochondrial substrate supply and utilization were similar between experimental treatments. The outcome of the present study is in line with recent reports showing that upregulation of UCP3 using physiological models like fasting does not affect mitochondrial proton leak $(14,16)$ but is in contrast with in vivo observations noted in UCP3 knockout mice (13).

Table 2

Muscle metabolites

\begin{tabular}{|c|c|c|c|c|c|c|c|c|}
\hline \multirow[t]{2}{*}{$\begin{array}{l}\text { Time } \\
\text { (s) }\end{array}$} & \multicolumn{2}{|c|}{$\begin{array}{c}\text { Creatine } \\
(\mathrm{mmol} / \mathrm{kg} \mathrm{dw})\end{array}$} & \multicolumn{2}{|c|}{$\begin{array}{c}\text { Lactate } \\
(\mathrm{mmol} / \mathrm{kg} \mathrm{dw})\end{array}$} & \multicolumn{2}{|c|}{$\begin{array}{l}\text { Free carnitine } \\
(\mathrm{mmol} / \mathrm{kg} \mathrm{dw})\end{array}$} & \multicolumn{2}{|c|}{$\begin{array}{l}\text { Acetylcarnitine } \\
(\mathrm{mmol} / \mathrm{kg} \mathrm{dw})\end{array}$} \\
\hline & Low fat & High fat & Low fat & High fat & Low fat & High fat & Low fat & High fat \\
\hline 20 & $95.2(20.7)$ & $100.0(16.6)$ & $66.6(28.7)$ & $59.5(19.5)$ & $11.2(4.6)$ & $11.6(5.4)$ & $11.5(2.8)$ & $10.7(3.3)$ \\
\hline 60 & $66.7(8.3)$ & $69.5(8.3)$ & $50.0(20.8)$ & $50.8(21.1)$ & $10.2(4.5)$ & $11.0(4.8)$ & $12.8(2.7)$ & $11.8(3.3)$ \\
\hline 120 & $55.5(5.1)$ & $54.9(5.3)$ & $33.4(13.0)$ & $30.8(14.4)$ & $10.0(3.8)$ & $10.6(4.8)$ & $12.7(1.7)$ & $12.6(3.3)$ \\
\hline
\end{tabular}

Muscle creatine, lactate, free-carnitine, and acetylcarnitine concentrations during recovery from 20 maximal knee extensions with limb blood flow occluded Immediately after exercise, limb blood flow was reinstated, and needle muscle biopsies were taken 20,60 , and 120 seconds after the cessation of exercise. Values represent means \pm SD. dw, dry weight. 


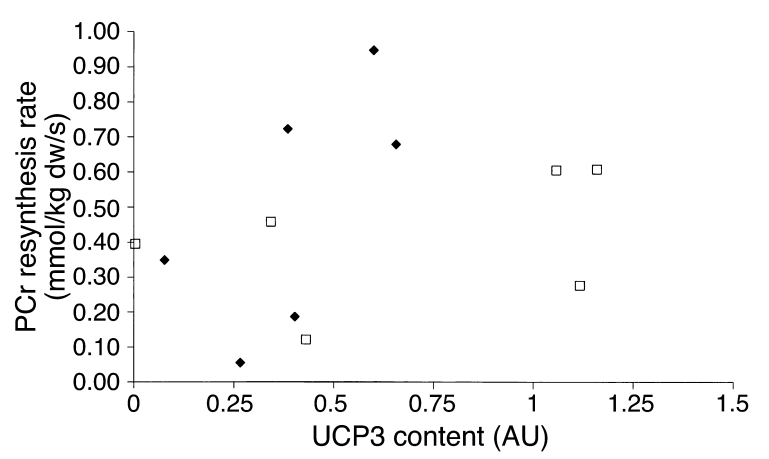

Figure 5

Relationship between UCP3 protein content (arbitrary units) and $\mathrm{PCr}$ resynthesis rates $(\mathrm{mmol} / \mathrm{kg} \mathrm{dw} / \mathrm{s})$. The filled diamonds represent the LF diet, and the open squares represent the HF diet. Note the lack of relation between $\mathrm{PCr}$ resynthesis rate and $\mathrm{UCP} 3$ content.

It could be argued that the determination of muscle $\mathrm{PCr}$ concentration in the present experiment was not sufficiently sensitive enough to detect any change in mitochondrial function caused by the observed increase in UCP3 protein content, and/or that the magnitude of increase in UCP3 induced by the HF feeding was simply insufficient to affect mitochondrial coupling. However, previous studies in our laboratory using the same experimental model as that used in the present study have shown clear differences in the rates of $\mathrm{PCr}$ resynthesis during recovery from ischemic contraction when mitochondrial substrate availability has been altered $(24,40,41)$, suggesting that the determination of $\mathrm{PCr}$ resynthesis is indeed a sensitive marker of mitochondrial function in vivo. Furthermore, recent quantitative assessments of UCP3 protein content calibrated with purified recombinant UCP3 showed that the abundance of UCP3 in skeletal muscle is 200- to 700-fold lower than that of UCP1 in brown adipose tissue (7). Therefore, the discrepancy in findings between studies in which UCP3 has been modestly increased by physiological intervention (such as fasting) and those in which UCP3 has been overexpressed to supraphysiological levels could be explained by differences in the absolute amount of UCP3 present.

Indeed, it was shown that transfection of yeast mitochondria with recombinant human UCP3 did not affect proton conductance markedly until UCP3 was increased to supraphysiological levels - that is, exceeding $700 \%$ of the UCP3 concentration reported in rat skeletal muscle (7). These findings have recently been confirmed in mitochondria from transgenic mice overexpressing or lacking UCP3 and have led to the conclusion that the uncoupling observed in models exhibiting supraphysiological amounts of $\mathrm{UCP} 3$ protein is an artifact of the model used and does not represent native uncoupling activity of the protein $(6,7,42)$. After our HF dietary intervention, UCP3 protein content increased by $44 \%$. On the basis of an extrapolation of the reference concentrations reported for UCP3 by Harper and colleagues (7), this increase would be insufficient to affect mitochondrial coupling.

It could also be reasoned that, in order to maintain ATP levels, the diet-induced increase in UCP3 protein was counterbalanced by downregulation of other uncoupling proteins present in skeletal muscle (e.g., UCP2). Recent reports have shown that, although present at the mRNA level, expression of UCP2 at the protein level in skeletal muscle is debatable (43). However, to exclude any potential counter-regulatory effect of UCP2, we measured UCP2 mRNA expression. In line with other reports using increased fatty acid availability as a model $(20,21,44)$, we found that UCP2 mRNA expression was increased on the HF diet, although this effect failed to reach significance $(4.00 \pm 1.44 \mathrm{amol} / \mathrm{g}$ RNA after HF vs. $2.73 \pm 0.80$ $\mathrm{amol} / \mathrm{g}$ RNA after LF, $P=0.07)$. Judging by the increase in UCP2 mRNA, it is conceivable that UCP2 protein expression increases rather than decreases if expression of UCP2 at the protein level occurs at all. Thus, it is not very likely that downregulation of UCP2 compensated for the increase in UCP3 protein content. However, we cannot exclude the possibility that downregulation of other yet unknown proteins mediating a proton leak interfere with the outcome of the present study.

Although the association between UCP3 levels and energy expenditure is frequently reported $(3,4$, 45-47) the results of the present study show that under conditions of forced maximum flow through the $\mathrm{F}_{0}-\mathrm{F}_{1}$-ATPase, increased UCP3 expression had no major effect on mitochondrial function. This finding is in line with the observation that subjects with an apparent null mutation of UCP3 possess no phenotypic aberration with regard to systemic or mitochondrial respiration (48). However, this does not exclude the possibility that under certain conditions, mild uncoupling - as a secondary effect of the primary role of UCP3 - may still occur, thus affecting energy expenditure. This is exemplified by a recent report by Harper et al. showing that successful loss of body mass following a low-calorie diet coincided with higher UCP3 mRNA expression and increased state 4 respiration (47). Although state 4 respiration reflects mitochondrial coupling under resting conditions in vitro, we report no effect of UCP3 protein content on mitochondrial function when flux through $\mathrm{F}_{0}-\mathrm{F}_{1^{-}}$ ATPase is forced to its maximum. It would be of interest to examine in vivo mitochondrial function in the diet-resistant and diet-responsive subjects from the study by Harper et al. and relate this to UCP3 protein rather than to mRNA levels.

In our search to determine the primary physiological role of UCP3, we have recently reevaluated the available data from studies involving human volunteers and postulated that UCP3 might act as a mitochondrial fatty acid anion exporter under conditions when fatty acid delivery to the mitochondria exceeds 
its capacity to oxidize fatty acids, rather than acting as an uncoupling protein per se (49). Involvement of UCP3 in fatty acid handling has previously been suggested, as it was shown that carriers of the exon 6 splice donor mutation had lower fat oxidation rates than noncarriers, without an effect on whole-body energy expenditure (50).

Since long-chain fatty acids can only be diverted to $\beta$-oxidation after acylation (as fatty-acyl-CoA) and the mitochondrial matrix lacks long-chain fatty-acyl-CoA synthetase, it is crucial for proper oxidation of longchain fatty acids to enter the mitochondria through the carnitine-acyl-tranferase system. However, if cytosolic fatty acid levels rise - for example, because of a mismatch between fatty acid availability and oxidative capacity, as is the case with prolonged consumption of an HF diet - fatty acids may partition in the mitochondrial membrane and enter the mitochondrial matrix through flip-flop (51). Because of the lack of long-chain fatty-acyl-CoA synthetase inside the matrix, these fatty acids can not be oxidized and will equilibrate with the $\mathrm{pH}$ gradient. Thus, neutral fatty acids and fatty acid anions may accumulate within the mitochondria and hamper mitochondrial function. Similar to UCP1 (52), UCP3 can export nonmetabolizable fatty acid anions from the mitochondrial matrix toward the intermembrane space, which will decrease the transmitochondrial membrane potential, with mild uncoupling as a secondary consequence. The increase in UCP3 protein levels, already observed after a 7-day HF diet, is consistent with this hypothesis. Furthermore, a lack of UCP3 will eventually lead to accumulation of fatty acids inside the matrix and to disturbances in fatty acid oxidation, which is consistent with reported aberrations in fat oxidation in humans with the exon 6 splice donor mutation (50) and in UCP3 knockout mice (33).

In summary, the present study demonstrated that upregulation of UCP3 by a physiological intervention (HF feeding) did not affect the postexercise rate of $\mathrm{PCr}$ resynthesis and thereby mitochondrial coupling when flux through the $\mathrm{F}_{0}-\mathrm{F}_{1}$-ATPase was likely to have been close to maximal. It is concluded that the primary role of UCP3 in human skeletal muscle is not mitochondrial uncoupling.

\section{Acknowledgments}

P. Schrauwen was supported by a grant from The Netherlands Organization for Scientific Research. We thank Lawrence J. Slieker from Eli Lilly for providing us with the UCP antibody.

1. Boss, O., et al. 1997. Uncoupling protein-3: a new member of the mitochondrial carrier family with tissue-specific expression. FEBS Lett. 408:39-42.

2. Ricquier, D., and Bouillaud, F. 2000. The uncoupling protein homologues: UCP1, UCP2, UCP3, StUCP and AtUCP. Biochem. J. 345:161-179.

3. Bouchard, C., Perusse, L., Chagnon, Y.C., Warden, C., and Ricquier, D. 1997. Linkage between markers in the vicinity of the uncoupling protein 2 gene and resting metabolic rate in humans. Hum. Mol. Genet. 6:1887-1889.
4. Schrauwen, P., Xia, J., Bogardus, C., Pratley, R.E., and Ravussin, E. 1999. Skeletal muscle uncoupling protein 3 expression is a determinant of energy expenditure in Pima Indians. Diabetes. 48:146-149.

5. Stuart, J.A., Harper, J.A., Brindle, K.M., Jekabsons, M.B., and Brand, M.D. 2001. A mitochondrial uncoupling artifact can be caused by expression of uncoupling protein 1 in yeast. Biochem. J. 356:779-789.

6. Cadenas, S., et al. 2002. The basal proton conductance of skeletal muscle mitochondria from transgenic mice overexpressing or lacking uncoupling protein-3. J. Biol. Chem. 277:2773-2778.

7. Harper, J.A., et al. 2002. Artifactual uncoupling by uncoupling protein 3 in yeast mitochondria at the concentrations found in mouse and rat skeletal-muscle mitochondria. Biochem. J. 361:49-56.

8. Gong, D.W., He, Y., Karas, M., and Reitman, M. 1997. Uncoupling protein-3 is a mediator of thermogenesis regulated by thyroid hormone, $\beta 3$-adrenergic agonists, and leptin. J. Biol. Chem. 272:24129-24132.

9. Zhang, C.Y., Hagen, T., Mootha, V.K., Slieker, L.J., and Lowell, B.B. 1999. Assessment of uncoupling activity of uncoupling protein 3 using a yeast heterologous expression system. FEBS Lett. 449:129-134.

10. Clapham, J.C., et al. 2000. Mice overexpressing human uncoupling protein-3 in skeletal muscle are hyperphagic and lean. Nature. 406:415-418.

11. Vidal-Puig, A.J., et al. 2000. Energy metabolism in uncoupling protein 3 gene knockout mice. J. Biol. Chem. 275:16258-16266.

12. Gong, D.W., et al. 2000. Lack of obesity and normal response to fasting and thyroid hormone in mice lacking uncoupling protein-3. J. Biol. Chem. 275:16251-16257.

13. Cline, G.W., et al. 2001. In vivo effects of uncoupling protein-3 gene disruption on mitochondrial energy metabolism. J. Biol. Chem. 276:20240-20244

14. Cadenas, S., et al. 1999. UCP2 and UCP3 rise in starved rat skeletal muscle but mitochondrial proton conductance is unchanged. FEBS Lett. 462:257-260.

15. Jucker, B.M., et al. 2000. 13C/31P NMR assessment of mitochondrial energy coupling in skeletal muscle of awake fed and fasted rats: relationship with uncoupling protein 3 expression. J. Biol. Chem. 275:39279-39286.

16. Jucker, B.M., et al. 2000. Assessment of mitochondrial energy coupling in vivo by $13 \mathrm{C} / 31 \mathrm{P}$ NMR. Proc. Natl. Acad. Sci. USA. 97:6880-6884.

17. de Lange, P., et al. 2001. Uncoupling protein-3 is a molecular determinant for the regulation of resting metabolic rate by thyroid hormone. Endocrinology. 142:3414-3420.

18. Boehm, E.A., Jones, B.E., Radda, G.K., Veech, R.L., and Clarke, K. 2001. Increased uncoupling proteins and decreased efficiency in palmitateperfused hyperthyroid rat heart. Am. J. Physiol. Heart Circ. Physiol. 280:H977-H983.

19. Lanni, A., et al. 1999. Expression of uncoupling protein-3 and mitochondrial activity in the transition from hypothyroid to hyperthyroid state in rat skeletal muscle. FEBS Lett. 444:250-254.

20. Surwit, R.S., et al. 1998. Diet-induced changes in uncoupling proteins in obesity-prone and obesity-resistant strains of mice. Proc. Natl. Acad. Sci. USA. 95:4061-4065.

21. Samec, S., Seydoux, J., and Dulloo, A.G. 1999. Post-starvation gene expression of skeletal muscle uncoupling protein 2 and uncoupling protein 3 in response to dietary fat levels and fatty acid composition: a link with insulin resistance. Diabetes. 48:436-441.

22. Schrauwen, P., Hoppeler, H., Billeter, R., Bakker, A., and Pendergast, D. 2001. Fiber type dependent upregulation of human skeletal muscle UCP2 and UCP3 mRNA expression by high-fat diet. Int. J. Obes. Relat. Metab. Disord. 25:449-456.

23. Bergström, J., and Hultman, E. 1966. Muscle glycogen synthesis after exercise: an enhancing factor localized to the muscle cells in man. Nature. 210:309-310.

24. Greenhaff, P.L., Bodin, K., Soderlund, K., and Hultman, E. 1994. Effect of oral creatine supplementation on skeletal muscle phosphocreatine resynthesis. Am. J. Physiol. 266:E725-E730.

25. Siri, W.R. 1956. The gross composition of the body. Adv. Biol. Med. Physiol. 4:239-280.

26. Stichting-Nederlandse-Voedingsstoffenbestand. 1996. NEVO table. Voorlichtingsbureau voor de voeding. The Hague, The Netherlands. 235 pp.

27. Harris, J.A., and Benedict, F.G.A. 1919. A biometric study of basal metabolism in man. Carnegie Institution of Washington. Washington, DC, USA. 223-251.

28. Westerterp, K.R. 2001. Pattern and intensity of physical activity. Nature. 410:539.

29. Harris, R.C., Hultman, E., and Nordesjo, L.O. 1974. Glycogen, glycolytic intermediates and high-energy phosphates determined in biopsy samples of musculus quadriceps femoris of man at rest. Methods and variance of values. Scand. J. Clin. Lab. Invest. 33:109-120.

30. Cederblad, G., Carlin, J.I., Constantin-Teodosiu, D., Harper, P., and 
Hultman, E. 1990. Radioisotopic assays of CoASH and carnitine and their acetylated forms in human skeletal muscle. Anal. Biochem. 185:274-278.

31. Laemmli, U.K. 1970. Cleavage of structural proteins during the assembly of the head of bacteriophage T4. Nature. 227:680-685.

32. Hesselink, M.K., et al. 2001. Protein expression of UCP3 differs between human type 1 , type $2 \mathrm{a}$, and type $2 \mathrm{~b}$ fibers. FASEB $J$. 15:1071-1073.

33. Bezaire, V., Hofmann, W., Kramer, J.K., Kozak, L.P., and Harper, M.E. 2001. Effects of fasting on muscle mitochondrial energetics and fatty acid metabolism in Ucp3(-/-) and wild-type mice. Am. J. Physiol. Endocrinol. Metab. 281:E975-E982.

34. Harris, R.C., et al. 1976. The time course of phosphorylcreatine resynthesis during recovery of the quadriceps muscle in man. Pflügers Arch. 367:137-142.

35. Erickson-Viitanen, S., Viitanen, P., Geiger, P.J., Yang, W.C., and Bessman, S.P. 1982. Compartmentation of mitochondrial creatine phosphokinase. I. Direct demonstration of compartmentation with the use of labeled precursors. J. Biol. Chem. 257:14395-14404.

36. Constantin-Teodosiu, D., Cederblad, G., and Hultman, E. 1993. PDC activity and acetyl group accumulation in skeletal muscle during isometric contraction. J. Appl. Physiol. 74:1712-1718.

37. Kariman, K., Chance, B., Burkhart, D.S., and Bolinger, L.A. 1986 Uncoupling effects of 2,4-dinitrophenol on electron transfer reactions and cell bioenergetics in rat brain in situ. Brain Res. 366:300-306.

38. Ren, J.M., and Hultman, E. 1989. Regulation of glycogenolysis in human skeletal muscle. J. Appl. Physiol. 67:2243-2248.

39. Söderlund, K., and Hultman, E. 1990. ATP content in single muscle fibers from human skeletal muscle after electrical stimulation and during recovery. Acta Physiol. Scand. 139:459-466.

40. Jones, S., Constantin-Teodosiu, D., Hultman, E., and Greenhaff, P.L. 2001. The creatine-mediated increase in muscle phosphocreatine resynthesis during recovery from maximal exercise in humans is associated with increased mitochondrial acetyl group utilisation. J. Physiol. 531P:66P.

41. Campbell, S.P., Hultman, E., Constantin-Teodosiu, D., and Greenhaff,
P.L. 2000. Acetyl group delivery limits mitochondrial flux in human skeletal muscle. J. Physiol. 523P:189P.

42. Echtay, K.S., et al. 2002. Superoxide activates mitochondrial uncoupling proteins. Nature. 415:96-99.

43. Pecqueur, C., et al. 2001. Uncoupling protein 2, in vivo distribution, induction upon oxidative stress, and evidence for translational regulation. J. Biol. Chem. 276:8705-8712.

44. Millet, L., et al. 1997. Increased uncoupling protein-2 and -3 mRNA expression during fasting in obese and lean humans. J. Clin. Invest. 100:2665-2670.

45. Schrauwen, P., Troost, F.J., Xia, J., Ravussin, E., and Saris, W.H. 1999. Skeletal muscle UCP2 and UCP3 expression in trained and untrained male subjects. Int. J. Obes. Relat. Metab. Disord. 23:966-972.

46. Walder, K., et al. 1998. Association between uncoupling protein polymorphisms (UCP2-UCP3) and energy metabolism/obesity in Pima Indians. Hum. Mol. Genet. 7:1431-1435.

47. Harper, M.E., et al. 2002. Decreased mitochondrial proton leak and reduced expression of uncoupling protein 3 in skeletal muscle of obese diet-resistant women. Diabetes. 51:2459-2466.

48. Chung, W.K., et al. 1999. Genetic and physiologic analysis of the role of uncoupling protein 3 in human energy homeostasis. Diabetes. 48:1890-1895.

49. Schrauwen, P., Saris, W.H., and Hesselink, M.K. 2001. An alternative function for human uncoupling protein 3: protection of mitochondria against accumulation of nonesterified fatty acids inside the mitochondrial matrix. FASEB J. 15:2497-2502.

50. Argyropoulos, G., et al. 1998. Effects of mutations in the human uncoupling protein 3 gene on the respiratory quotient and fat oxidation in severe obesity and type 2 diabetes. J. Clin. Invest. 102:1345-1351.

51. Hamilton, J.A., and Kamp, F. 1999. How are free fatty acids transported in membranes? Is it by proteins or by free diffusion through the lipids? Diabetes. 48:2255-2269.

52. Jezek, P., Orosz, D.E., Modriansky, M., and Garlid, K.D. 1994. Transport of anions and protons by the mitochondrial uncoupling protein and its regulation by nucleotides and fatty acids. A new look at old hypotheses. J. Biol. Chem. 269:26184-26190. 